\title{
Patterns of sensitization to aeroallergens and their effect on airway hyper-responsiveness in Busan, Korea
}

\author{
Eun-Jung Jo, ${ }^{1,2,3}$ Jung Seop Eom, ${ }^{1,2,3}$ Jeongha Mok, ${ }^{1,2,3}$ Mi-Hyun Kim, ${ }^{1,2,3}$ Kwangha Lee, ${ }^{1,2,3}$ \\ Ki Uk Kim, ${ }^{1,2,3}$ Min Ki Lee, ${ }^{1,2,3}$ Hye-Kyung Park ${ }^{1,2,3}$
}

\begin{abstract}
Background: Allergen sensitization and its influence on allergic disease can vary depending on ethnicity and geography.

Objective: To investigate aeroallergen sensitization patterns and their effect on airway hyper-responsiveness (AHR) in Busan, Korea.

Methods: We reviewed data for subjects who attended for evaluation of respiratory symptoms between 2011 and 2016. The skin test results of 16 allergens (Dermatophagoides pteronyssinus, Dermatophagoides farinae, cat, dog, Alternaria, Aspergillus fumigatus, early blossoming tree pollen mix, late blossoming tree pollen mix, alder, birch, oak, grass mix, mugwort, ragweed, and Japanese hop) were analyzed. Age was categorized as group I (15 to $<65$ years) or group II ( $\geq$ 65 years).
\end{abstract}

Results: A total of 2,791 subjects were analyzed (mean age: 50.9 years, female $61.3 \%$ ). AHR was demonstrated in $15.8 \%$; sputum eosinophilia in $12.1 \%$; and atopy in $31.2 \%$. The most commonly sensitizing allergen was house dust mite (17.4\% to $D$. pteronyssinus and $17.9 \%$ to $D$. farinae), followed by late blossoming tree pollen mix (8.8\%) and early blossoming tree pollen mix (8.6\%). AHR was associated with sensitization to D. pteronyssinus, D. farina, Alternaria, dog, cat, alder, birch, oak, and mugwort. However, group II did not show any associations between AHR and any of the aeroallergens except D. farina. Multiple logistic regression analyses showed that the independent factors for AHR were ever-smoker status, D. farina, and oak sensitization.

Conclusions: Sensitization to house dust mites and tree pollen was found to be common in Busan. These aeroallergens significantly affected AHR, particularly in the younger group.

Key words: allergens, airway hyper-responsiveness, prevalence, sensitization, skin test

\footnotetext{
Affiliations:

${ }^{1}$ Department of Internal Medicine, Pusan National University School of Medicine, Busan,

${ }^{2}$ Department of Internal Medicine, Pusan National University Hospital, Busan,

${ }^{3}$ Biomedical Research Institute, Pusan National University Hospital, Busan, South Korea

Corresponding author:

Hye-Kyung Park

Department of Internal Medicine, Pusan National University Hospital, Pusan National University School of Medicine,

179 Gudeok-ro, Seo-gu, Busan, 49241, Korea

E-mail: parkhk@pusan.ac.kr
}

\section{Introduction}

Sensitization to allergens is a critical step in the induction of allergies. Allergic diseases induced by aeroallergens have various clinical manifestations. Airway hyper-responsiveness (AHR) is a major component of asthma, and previous studies have reported an association between sensitization to specific aeroallergens and the development of asthma or AHR. In particular, perennial allergen sensitization, such as that to house dust mites (HDM) or cats, is an important factor in AHR. ${ }^{1-3}$ However, sensitization to pollen has a relatively low impact on the presence of asthma symptoms or AHR.,4

Allergen sensitization patterns vary depending on ethnicity and geography; thus, their influence on allergic diseases likely varies by region. In a study of inland patients in Korea, AHR was associated with sensitization to perennial allergens 
rather than seasonal allergens. ${ }^{5}$ Busan is the second largest city in the Republic of Korea. Because the southern end of Busan meets the sea and the northern end is surrounded by mountains, the city's weather is warm and humid. Although Busan is urban, we hypothesized that the aeroallergen pattern and its effect on AHR in Busan differ from those in other cities in Korea. Therefore, we analyzed the allergen sensitization patterns and the factors that affect AHR in Busan.

\section{Methods \\ Study subjects}

We retrospectively reviewed data from all patients who underwent skin prick testing for aeroallergens to evaluate their chronic respiratory symptoms between 2011 and 2016. The results of the skin prick tests, methacholine bronchial provocation test, and an induced sputum analysis were analyzed. If the patient was taking any medications prescribed by another clinic, such as antihistamines or antidepressants, which might affect the results, the tests were performed after withdrawing the medication for at least $72 \mathrm{~h}$ prior to testing. Age was categorized as group I ( 15 to $<65$ years) or group II ( $\geq 65$ years). This study was approved by our institutional review board (H-1809-016-071).

\section{Methacholine bronchial provocation test}

Baseline spirometry was performed using a Vmax Encore 20 (CareFusion Respiratory Care Inc., Yorba Linda, CA, USA). A bronchial provocation test was not administered to patients with a forced expiratory volume in $1 \mathrm{~s}\left(\mathrm{FEV}_{1}\right)$ of $<$ $60 \%$ of predicted. Methacholine dilutions of $0.625,1.25,2.5$, 5,10 , and $25 \mathrm{mg} / \mathrm{mL}$ were used. The methacholine challenge was performed using a five-breath protocol and the Aerosol Provocation System (CareFusion Respiratory Care). Spirometry was performed after $90 \mathrm{~s}$. The test ended when a decrease of $\geq 20 \%$ was achieved compared with the baseline $\mathrm{FEV}_{1}$ or when the highest concentration of methacholine was inhaled. The provocation concentration that caused a decrease of $20 \%$ in $\mathrm{FEV}_{1}$ was expressed as the $\mathrm{PC}_{20}$ (provocation concentration dose of methacholine). AHR was defined as a $\mathrm{PC}_{20}<16 \mathrm{mg} /$ $\mathrm{mL}$.

\section{Induced sputum processing and analysis}

Sputum induction and processing were carried out according to a standardized protocol as described previously. ${ }^{6}$ The subjects inhaled nebulized $4.5 \%$ saline via an ultrasonic nebulizer. The subjects spat the sputum into a Petri dish every 5 min after the start of nebulization. Following addition $0.01 \mathrm{M}$ dithiothreitol, the samples were vortex-mixed, shaken for 30 min at room temperature, and filtered through a $100-\mu \mathrm{m}$ cell strainer. The cells were collected by centrifugation $(2,000 \mathrm{rpm}$, $4^{\circ} \mathrm{C}$ for $10 \mathrm{~min}$ ) and suspended in $1 \mathrm{ml}$ of phosphate-buffered saline. Leukocytes, bronchial epithelial cells, and squamous cells were counted after staining with Hemacolor ${ }^{\circledR}$ Rapid Stain in the Blood Smear Staining Set for microscopy (Merck, Darmstadt, Germany).

\section{Skin prick test to aeroallergens}

The subjects underwent skin prick tests to 55 aeroallergens. Allergopharma allergen extracts were employed for the skin prick tests. Normal saline $(0.9 \%)$ and histamine $(1 \mathrm{mg} /$ $\mathrm{mL}$ ) were used as the negative and positive controls, respectively. The wheal diameter was measured 15 min after application. The skin prick test reactions were graded by the ratio of the allergen wheal diameter to the histamine wheal diameter (A/H ratio), and were considered positive when the $\mathrm{A} / \mathrm{H}$ ratio was $\geq 1$. Atopy was defined as a positive skin test response to at least one allergen. In addition, grades $1+$ to $4+$ were assigned according to the $\mathrm{A} / \mathrm{H}$ ratio. Grade $2+$ indicated an $\mathrm{A} / \mathrm{H}$ ratio $\geq 0.5$, and each additional plus indicated a doubling of the ratio. ${ }^{5}$

Associations between AHR and inhalant allergens were assessed using 16 inhalant allergens, considering non-crossacting allergens, commonly sensitized with reference to a study conducted in Korea, ${ }^{7}$ including Dermatophagoides pteronyssinus, Dermatophagoides farinae, cat, dog, Alternaria, Aspergillus fumigatus, early blossoming tree pollen mix (alder, hazel, poplar, elm, and willow), late blossoming tree pollen mix (birch, beech, oak, and plane), alder, birch, oak, grass mix (kentucky blue, meadow, orchard, rye, timothy, and velvet grasses), mugwort, ragweed, and Japanese hop.

\section{Statistical analysis}

All statistical analyses were performed using SPSS software (ver. 22.0 for Windows; SPSS Inc., Chicago, IL, USA). Data are presented as numbers and percentages for categorical variables and as mean \pm SD for continuous variables. Comparisons between variables were performed by using Pearson's chi-square test or Fisher's exact test for categorical variables or the Student's $t$-test for continuous variables. A logistic regression analysis was performed to obtain the adjusted odds ratios (ORs) and 95\% confidence intervals (CIs) for the independent effect that sensitization to each allergen had on AHR or airway eosinophilic inflammation. Then, the potentially relevant factors were included in multiple logistic regression analyses. Multiple logistic regression analyses were performed using the backward elimination method to remove the independent variables one-by-one that were less likely through the likelihood ratio tests. Spearman's correlation test was used to evaluate the relationship between the severity of AHR and the skin prick test results. Linear-by-linear association was used to analyze the association between AHR and increasing grade on the skin prick tests. $P$-values $<0.05$ were considered significant.

\section{Results \\ Clinical characteristics of the study subjects}

A total of 2,791 subjects were analyzed (mean age $50.9 \pm$ 16.1 years; $61.3 \%$ female). AHR was demonstrated in $15.8 \%$, sputum eosinophilia in $12.1 \%$, and sensitization to at least one aeroallergen in skin tests was detected in $31.2 \%$. Their diagnoses were asthma, allergic rhinitis, non-allergic rhinitis, chronic rhinosinusitis, eosinophilic bronchitis, and chronic obstructive pulmonary disease (COPD) (Table 1). The most commonly sensitizing allergen was HDM, followed by 
Table 1. Clinical characteristics of the population.

\begin{tabular}{|c|c|c|c|c|}
\hline Characteristics & $\begin{array}{c}\text { Total } \\
(\mathrm{N}=2,791)\end{array}$ & $\begin{array}{c}\text { Group I } \\
(\mathbf{N}=2,166)\end{array}$ & $\begin{array}{l}\text { Group II } \\
(N=625)\end{array}$ & $P$ \\
\hline Age, mean \pm SD & $50.9 \pm 16.1$ & $45.2 \pm 13.5$ & $70.7 \pm 4.6$ & $<0.001$ \\
\hline Female, n (\%) & $1,710(61.3 \%)$ & $1,310(60.5 \%)$ & $400(64.0 \%)$ & 0.112 \\
\hline \multicolumn{5}{|l|}{ Smoking, $\mathrm{N}=1,881$} \\
\hline Ever-smoker, n (\%) & $563(29.9 \%)$ & $425(29.2 \%)$ & $138(32.3 \%)$ & 0.220 \\
\hline Never-smoker, n (\%) & $1,318(70.1 \%)$ & $1,029(70.8 \%)$ & $289(67.7 \%)$ & \\
\hline Pack•years, mean \pm SD & $31.6 \pm 172.6$ & $31.6 \pm 194.7$ & $31.6 \pm 26.1$ & 0.539 \\
\hline Airway hyper-responsiveness ${ }^{*}, \mathrm{n}(\%), \mathrm{N}=2,415$ & $382(15.8 \%)$ & $284(15.1 \%)$ & $98(18.4 \%)$ & 0.069 \\
\hline Airway eosinophilia $^{\dagger}, \mathrm{n}(\%), \mathrm{N}=1,867$ & $226(12.1 \%)$ & $182(12.2 \%)$ & $44(11.8 \%)$ & 0.822 \\
\hline Atopy ${ }^{\ddagger}, \mathrm{n}(\%)$ & $870(31.2 \%)$ & $781(36.1 \%)$ & $89(14.2 \%)$ & $<0.001$ \\
\hline \multicolumn{5}{|l|}{ Diagnosis, n (\%) } \\
\hline Allergic rhinitis & $697(25.0 \%)$ & $609(28.1 \%)$ & $88(14.1 \%)$ & $<0.001$ \\
\hline Non-allergic rhinitis & $172(6.2 \%)$ & $128(5.9 \%)$ & $44(7.0 \%)$ & 0.301 \\
\hline Chronic rhinosinusitis & $511(18.3 \%)$ & $361(16.7 \%)$ & $150(24.0 \%)$ & $<0.001$ \\
\hline Bronchial asthma & $840(30.1 \%)$ & $630(29.1 \%)$ & $210(33.6 \%)$ & 0.030 \\
\hline Eosinophilic bronchitis & $200(7.2 \%)$ & $175(8.1 \%)$ & $25(4.0 \%)$ & $<0.001$ \\
\hline Chronic obstructive pulmonary disease & $49(1.8 \%)$ & $19(0.9 \%)$ & $30(4.8 \%)$ & $<0.001$ \\
\hline
\end{tabular}

* PC20 (provocation concentration dose of methacholine) $\leq 16 \mathrm{mg} / \mathrm{mL}$

${ }^{\dagger}$ Sputum eosinophil count $\geq 3 \%$

* Positive skin test response to at least one allergen

Table 2. Aeroallergen sensitization patterns.

\begin{tabular}{lcccc}
\multicolumn{1}{c}{ Aeroallergen } & Total & Group I & Group II & $P$ \\
\hline D. pteronyssinus & $486(17.4 \%)$ & $464(21.4 \%)$ & $22(3.5 \%)$ & $<0.001$ \\
D. farina & $499(17.9 \%)$ & $467(21.6 \%)$ & $32(5.1 \%)$ & $<0.001$ \\
Alternaria & $23(0.8 \%)$ & $23(1.1 \%)$ & 0 & 0.005 \\
Aspergillus & $13(0.5 \%)$ & $10(0.5 \%)$ & $3(0.5 \%)$ & 1.000 \\
Cockroach & $67(2.4 \%)$ & $57(2.6 \%)$ & $10(1.6 \%)$ & 0.138 \\
Dog epithelia & $61(2.2 \%)$ & $61(2.8 \%)$ & 0 & $<0.001$ \\
Cat epithelia & $107(3.8 \%)$ & $102(4.7 \%)$ & $5(0.8 \%)$ & $<0.001$ \\
Early blossoming tree pollen mix & $239(8.6 \%)$ & $205(9.5 \%)$ & $34(5.4 \%)$ & 0.002 \\
Late blossoming tree pollen mix & $245(8.8 \%)$ & $212(9.8 \%)$ & $33(5.3 \%)$ & $<0.001$ \\
Alder & $210(7.5 \%)$ & $181(8.4 \%)$ & $29(4.6 \%)$ & 0.002 \\
Birch & $201(7.2 \%)$ & $177(8.2 \%)$ & $24(3.8 \%)$ & $<0.001$ \\
Oak & $150(5.4 \%)$ & $127(5.9 \%)$ & $23(3.7 \%)$ & 0.033 \\
Grass mix & $39(1.4 \%)$ & $36(1.7 \%)$ & $3(0.5 \%)$ & 0.031 \\
\hline Mugwort & $94(3.4 \%)$ & $83(3.8 \%)$ & $11(1.8 \%)$ & 0.011 \\
\hline Japanese hop & $40(1.4 \%)$ & $34(1.6 \%)$ & $6(1.0 \%)$ & 0.259 \\
\hline
\end{tabular}


late blossoming tree pollen mix and early blossoming tree pollen mix (Table 2). The sensitization rates to the antigens were generally higher in group I than in group II (Table 2).

\section{Factors affecting airway hyper-responsiveness}

AHR-positive patients were younger (50.9 vs. 51.1 years; $P=0.002$ ) and distributed equally by gender. The frequency of ever-smokers was significantly higher in AHR-positive patients $(20.0 \%$ vs. $13.6 \%$; $P=0.001)$.
There were 2,415 patients who underwent both skin prick testing and AHR. We analyzed the sensitizing aeroallergens for affecting AHR after adjusting for age, gender, and smoking status (Table 3). AHR was significantly correlated with sensitization to D. pteronyssinus, D. farina, Alternaria, dog, cat, early blossoming tree pollen mix, late blossoming tree pollen mix, alder, birch, oak, and mugwort.

Table 3. Relationship between airway hyper-responsiveness (AHR) and sensitization to aeroallergens after adjusting for age, gender, and smoking status

\begin{tabular}{|c|c|c|c|c|c|c|}
\hline \multirow{2}{*}{ Aeroallergen } & \multicolumn{2}{|c|}{ Total } & \multicolumn{2}{|c|}{ Group I } & \multicolumn{2}{|c|}{ Group II } \\
\hline & OR $(95 \% \mathrm{CI})$ & $\boldsymbol{P}$ & OR $(95 \% \mathrm{CI})$ & $\boldsymbol{P}$ & OR $(95 \% \mathrm{CI})$ & $\boldsymbol{P}$ \\
\hline D. pteronyssinus & $\begin{array}{c}1.928 \\
(1.356-2.743)\end{array}$ & $<0.001$ & $\begin{array}{c}1.769 \\
(1.220-2.565)\end{array}$ & 0.003 & $\begin{array}{c}3.254 \\
(0.955-11.087)\end{array}$ & 0.059 \\
\hline D. farina & $\begin{array}{c}1.947 \\
(1.376-2.866)\end{array}$ & $<0.001$ & $\begin{array}{c}1.740 \\
(1.200-2.524)\end{array}$ & 0.004 & $\begin{array}{c}3.215 \\
(1.144-9.035)\end{array}$ & 0.027 \\
\hline Alternaria & $\begin{array}{c}3.338 \\
(1.181-9.439)\end{array}$ & 0.023 & $\begin{array}{c}3.120 \\
(1.104-8.818)\end{array}$ & 0.032 & $\begin{array}{c}2.047 \\
(0.868-4.825)\end{array}$ & 0.102 \\
\hline Aspergillus & $\begin{array}{c}1.640 \\
(0.324-8.295)\end{array}$ & 0.549 & $\begin{array}{c}1.780 \\
(0.336-9.439)\end{array}$ & 0.498 & - & - \\
\hline Cockroach & $\begin{array}{c}1.834 \\
(0.913-3.684)\end{array}$ & 0.089 & $\begin{array}{c}1.814 \\
(0.841-3.914)\end{array}$ & 0.129 & $\begin{array}{c}1.999 \\
(0.352-11.367)\end{array}$ & 0.435 \\
\hline Dog epithelia & $\begin{array}{c}2.181 \\
(1.008-4.723)\end{array}$ & 0.048 & $\begin{array}{c}2.028 \\
(0.933-4.408)\end{array}$ & 0.074 & $\begin{array}{c}2.047 \\
(0.868-4.825)\end{array}$ & 0.102 \\
\hline Cat epithelia & $\begin{array}{c}2.483 \\
(1.374-4.489)\end{array}$ & 0.003 & $\begin{array}{c}2.393 \\
(1.317-4.349)\end{array}$ & 0.004 & - & - \\
\hline Early blossoming tree pollen mix & $\begin{array}{c}1.662 \\
(1.069-2.583)\end{array}$ & 0.024 & $\begin{array}{c}1.983 \\
(1.238-3.177)\end{array}$ & 0.004 & $\begin{array}{c}0.473 \\
(0.105-2.123)\end{array}$ & 0.329 \\
\hline Late blossoming tree pollen mix & $\begin{array}{c}1.730 \\
(1.119-2.675)\end{array}$ & 0.014 & $\begin{array}{c}2.064 \\
(1.296-3.287)\end{array}$ & 0.002 & $\begin{array}{c}0.473 \\
(0.105-2.123)\end{array}$ & 0.329 \\
\hline Alder & $\begin{array}{c}1.867 \\
(1.178-2.958)\end{array}$ & 0.008 & $\begin{array}{c}2.207 \\
(1.350-3.610)\end{array}$ & 0.002 & $\begin{array}{c}0.577 \\
(0.126-2.647)\end{array}$ & 0.479 \\
\hline Birch & $\begin{array}{c}1.972 \\
(1.240-3.137)\end{array}$ & 0.004 & $\begin{array}{c}2.287 \\
(1.394-3.753)\end{array}$ & 0.001 & $\begin{array}{c}0.634 \\
(0.137-2.932)\end{array}$ & 0.560 \\
\hline Oak & $\begin{array}{c}2.185 \\
(1.293-3.691)\end{array}$ & 0.003 & $\begin{array}{c}2.741 \\
(1.568-4.790)\end{array}$ & $<0.001$ & $\begin{array}{c}0.355 \\
(0.045-2.822)\end{array}$ & 0.327 \\
\hline Grass mix & $\begin{array}{c}1.335 \\
(0.439-4.065)\end{array}$ & 0.611 & $\begin{array}{c}1.529 \\
(0.490-4.767)\end{array}$ & 0.464 & - & - \\
\hline Mugwort & $\begin{array}{c}1.998 \\
(1.107-3.608)\end{array}$ & 0.022 & $\begin{array}{c}1.861 \\
(0.973-3.559)\end{array}$ & 0.060 & $\begin{array}{c}3.148 \\
(0.675-14.686)\end{array}$ & 0.144 \\
\hline Ragweed & $\begin{array}{c}2.169 \\
(0.890-5.285)\end{array}$ & 0.089 & $\begin{array}{c}2.235 \\
(0.845-5.912)\end{array}$ & 0.105 & $\begin{array}{c}1.533 \\
(0.155-15.147)\end{array}$ & 0.715 \\
\hline Japanese hop & $\begin{array}{c}0.983 \\
(0.374-2.585)\end{array}$ & 0.973 & $\begin{array}{c}1.026 \\
(0.387-2.721)\end{array}$ & 0.958 & - & - \\
\hline
\end{tabular}


The risk factors for AHR were identified as ever-smoker status, D. farina, and oak sensitization when a multiple logistic regression analysis was performed after adjusting for gender, age, smoking status, and the sensitizing allergens affecting AHR (Table 4).

\section{Aeroallegen sensitization and severity of airway hyper-re- sponsiveness}

The correlation between the $\mathrm{PC}_{20}$ value and wheal size of the allergens showed that $\mathrm{PC}_{20}$ value was lower with increasing wheal size of $D$. pteronyssinus, D. farina, Alternaria, dog, and cat, but not with the seasonal allergens (Table 5). However, the association analysis of aeroallergen grade with AHR showed that AHR positivity was higher as the grade of most allergens (except Aspergillus, cockroach, and Japanese hop) increased (Table 6).

Table 4. Independent factors for AHR by multiple logistic regression analysis.

\begin{tabular}{|lcc|}
\hline \multicolumn{1}{l}{ Factors } & OR $(\mathbf{9 5 \%} \mathrm{CI})$ & $\boldsymbol{P}$ \\
\hline Age & $1.009(0.999-1.018)$ & 0.067 \\
\hline Ever-smoker & $1.561(1.183-2.059)$ & 0.002 \\
\hline D. farina & $1.704(1.187-2.447)$ & 0.004 \\
\hline Cat & $1.637(0.868-3.086)$ & 0.128 \\
\hline Alternaria & $2.523(0.862-7.387)$ & 0.091 \\
\hline Oak & $1.792(1.038-3.095)$ & 0.036 \\
\hline
\end{tabular}

Table 5. The correlation between the wheal size on skin prick tests and severity of airway hyper-responsiveness

\begin{tabular}{lcc}
\multicolumn{1}{c}{ Aeroallergen } & $\boldsymbol{\rho}$ & $\boldsymbol{P}$ \\
\hline D. pteronyssinus & -0.115 & 0.023 \\
D. farina & -0.117 & 0.021 \\
\hline Alternaria & -0.114 & 0.025 \\
\hline Aspergillus & -0.037 & 0.466 \\
\hline Cockroach & 0.058 & 0.259 \\
\hline Dog epithelia & -0.108 & 0.034 \\
Cat epithelia & -0.182 & $<0.001$ \\
\hline Early blossoming tree pollen mix & -0.032 & 0.532 \\
\hline Late blossoming tree pollen mix & -0.015 & 0.774 \\
Alder & -0.002 & 0.972 \\
Birch & -0.032 & 0.534 \\
Oak & -0.035 & 0.491 \\
\hline Grass mix & -0.048 & 0.345 \\
Mugwort & 0.005 & 0.917 \\
Ragweed & -0.041 & 0.421 \\
Japanese hop & -0.088 & 0.083 \\
\hline
\end{tabular}

Table 6. Airway hyper-responsiveness positivity according to grade of the skin prick tests.

\begin{tabular}{|c|c|c|c|c|c|c|}
\hline Aeroallergen & Grade 0 & Grade 1 & Grade 2 & Grade 3 & Grade 4 & $P$ \\
\hline D. pteronyssinus & $14.2 \%$ & $2.6 \%$ & $18.8 \%$ & $19.9 \%$ & $27.0 \%$ & $<0.001$ \\
\hline D. farina & $14.3 \%$ & $12.5 \%$ & $16.2 \%$ & $21.3 \%$ & $25.0 \%$ & $<0.001$ \\
\hline Alternaria & $15.3 \%$ & $12.5 \%$ & $48.0 \%$ & $21.4 \%$ & $83.3 \%$ & $<0.001$ \\
\hline Aspergillus & $15.8 \%$ & $22.2 \%$ & $14.3 \%$ & $25.0 \%$ & - & 0.581 \\
\hline Cockroach & $15.6 \%$ & $14.7 \%$ & $17.6 \%$ & $25.0 \%$ & $12.5 \%$ & 0.205 \\
\hline Dog epithelia & $14.7 \%$ & $22.2 \%$ & $28.7 \%$ & $28.1 \%$ & $38.5 \%$ & $<0.001$ \\
\hline Cat epithelia & $15.2 \%$ & $5.3 \%$ & $23.2 \%$ & $29.8 \%$ & $16.7 \%$ & 0.001 \\
\hline Early blossoming tree pollen mix & $15.0 \%$ & $54.5 \%$ & $11.7 \%$ & $19.8 \%$ & $30.7 \%$ & 0.001 \\
\hline Late blossoming tree pollen mix & $14.9 \%$ & $35.7 \%$ & $15.2 \%$ & $18.1 \%$ & $31.2 \%$ & $<0.001$ \\
\hline Alder & $15.0 \%$ & $30.8 \%$ & $16.4 \%$ & $20.2 \%$ & $31.6 \%$ & $<0.001$ \\
\hline Birch & $14.8 \%$ & $16.7 \%$ & $33.3 \%$ & $20.2 \%$ & $31.6 \%$ & $<0.001$ \\
\hline Oak & $15.0 \%$ & $25.0 \%$ & $17.2 \%$ & $25.3 \%$ & $42.4 \%$ & $<0.001$ \\
\hline Grass mix & $15.5 \%$ & $30.0 \%$ & $29.0 \%$ & $26.3 \%$ & $18.2 \%$ & 0.035 \\
\hline Mugwort & $15.4 \%$ & $16.7 \%$ & $21.2 \%$ & $31.4 \%$ & $16.0 \%$ & 0.014 \\
\hline Ragweed & $15.4 \%$ & $12.5 \%$ & $41.9 \%$ & $25.0 \%$ & $25.0 \%$ & 0.001 \\
\hline Japanese hop & $15.7 \%$ & $10.0 \%$ & $24.0 \%$ & $17.9 \%$ & $15.8 \%$ & 0.575 \\
\hline
\end{tabular}




\section{Aeroallergen sensitization and eosinophilic airway inflam- mation}

A total of 1,867 subjects underwent induced sputum analysis. Patients with eosinophilic airway inflammation were older (53.0 vs. 50.2 years; $P=0.007)$ but were distributed equally by gender, smoking status, and atopic status. Sensitization to each aeroallergen was not correlated with eosinophilic airway inflammation.

\section{Difference according to age group}

No differences were observed between groups I and II in AHR or airway eosinophilia. However, group II had significantly less atopy, allergic rhinitis, and eosinophilic bronchitis than group I. Chronic sinusitis, asthma, and COPD were significantly higher in group II than in group I (Table 1). The rate of allergen sensitization was low in group II, and the most sensitizing aeroallergens were the early blossoming tree pollen mix and late blossoming tree pollen mix, followed by $D$. $f a$ rina (Table 2). Ever-smoker status was associated with AHR in group I $(18.7 \%$ vs. $12.6 \% ; P=0.004)$, but not in group II. AHR was not associated with sensitization to any aeroallergen except D. farina in the elderly group (Table 3).

\section{Discussion}

We analyzed the patterns of sensitization to aeroallergens and the factors affecting AHR in patients with respiratory symptoms in Busan. The most common aeroallergen sensitizations were to HDM and tree pollen, and the factors that affected AHR were ever-smoking, D. farina, and oak sensitization. However, their effects were not detected in the elderly.

Sensitization patterns to inhalant allergens vary from region to region. A regional difference in the patterns of aeroallergen sensitization was also detected in Korea. Kang et al. reported patterns of inhalant allergen sensitization in Korean adults visiting 12 allergy clinics located in nine different areas in 2014. ${ }^{7}$ The commonly allergen sensitizations were to HDM, cats, tree pollen, and mugwort. The most common sensitizing antigens in all regions were HDM, and the next most common antigens differed by region. Pollen was the common antigen in the south. Cats were the next most common sensitizing antigen in the downtown area of Seoul and Gyeonggi-do. The common occurrence of pollen sensitization in the south is thought to be due to the warmer weather there, and it is thought that cat sensitization in urban areas is caused by the higher numbers of pets. Our study was conducted in Busan, located in the south; the most common antigen there was HDM, and the second most common antigen was pollen as also reported by Kang et al. However, the results of other research conducted in 2005 in Busan differed from those of our study. In 2005, Kim et al. reported that the sensitization rates of common inhalant allergens in $\mathrm{Bu}$ san were mites (37.9\%), animal epithelium (26.1\%), and tree pollen $(22.6 \%) .8$ The reasons for the differences in the results are presumed to be due to changes in the sensitization patterns over time and that $64 \%$ of the subjects in the study of $\mathrm{Kim}$ et al. were asthma patients. The antigen sensitization patterns were different in different time periods. Lee et al. analyzed the sensitization rate of major allergens, especially pollen allergens, from 1999 to 2008 in Gyeonggi-do.
The study found that the sensitization rates to allergens increased overall during that period, and that sensitization to pollen, such as alder, oak, mugwort, ragweed, Japanese hop, and timothy grass, increased significantly during that time. ${ }^{9}$ These changes have also been reported in other Asian regions. In Thai patients with asthma, $75.9 \%$ are sensitized to mites, followed by cockroaches, Bermuda grass, timothy grass, cats, and dogs. ${ }^{10} \mathrm{HDM}$ is the most common antigen, but the prevalence of sensitization to HDM remained steady over the 12 year period of the study. However, the prevalence of Bermuda grass and cat sensitization increased over time. ${ }^{10}$

Several studies have investigated the association between sensitization to specific aeroallergens and AHR. A study conducted on patients visiting a hospital in Gyeonggi-do from 2005 to 2011 showed that HDM, Alternaria, and cats were significant factors affecting AHR. ${ }^{5}$ A study of Korean adolescents showed that they were positive for $D$. pteronyssinus (40.7\%), D. farina (41.6\%), cockroaches (6.5\%), dogs (5.4\%), cats (6.1\%), mugwort (6.2\%), and Alternaria (4.7\%). ${ }^{11}$ The risk of developing AHR increases in patients sensitized to indoor and mold allergens. ${ }^{11}$ In a study of childhood asthma in New Zealand, the common allergens were rye grass pollen (32.5\%), HDM (30.1\%), and cat dander (13.3\%). Airway responsiveness was significantly associated with HDM and cat dander sensitization, but not grass. ${ }^{4}$ Almost all studies that investigated the effect of an aeroallergen on AHR showed that perennial allergen sensitization was a significant parameter. In those studies, seasonal allergens were not a predictor of bronchial hyper-responsiveness. ${ }^{12,13}$ Boulet et al. investigated the magnitudes of early asthmatic responses (EAR) and late asthmatic responses (LAR) in mildly asthmatic subjects according to the type of inhaled aeroallergen. ${ }^{14}$ The study showed that LAR was significantly more marked in subjects challenged with HDM than those challenged with an animal or pollen. ${ }^{14}$ The ratio of the EAR over the LAR was significantly lower in HDM compared with pollen allergen bronchoprovocation tests. This result suggests that different mechanisms may be involved in the magnitude of the LAR depending on the allergen type. The authors reported that LAR caused by HDM could be more marked when compared to seasonal allergens, due to an airway priming effect. HDM-sensitized individuals are chronically exposed to this allergen. Chronic exposure to allergens likely induces a greater increase in the allergenic response than periodic re-exposure. However, our study showed that pollen sensitization was a significant factor in AHR. This difference can be explained by the fact that pollen is a common antigen in Busan; differences in exposure duration or intensity of pollen may occur more frequently there compared to other regions. Therefore, conflicting results for seasonal allergens should be considered based on regional differences. Pollen is distributed in Korea from February to November. In general, tree pollen grains are observed from March to May. Among the pollen varieties, pine, oak, alder, and birch are the main species of pollen. ${ }^{15}$ However, the concentration of total pollen varies by the place. This is probably due to a difference in the vegetation distribution between different regions and the flowering times and scattering rates of each species depending on the weather conditions. Thiam et al. reported that Asian patients with atopy are more likely to have 
a HDM allergy (up to $90 \%$ vs. $50-70 \%$ ) than Western populations, and pollen and animal dander are less common than Western patients with asthma and allergic rhinitis. ${ }^{16}$ However, our research shows that there can be regional differences in Asia as well.

TePas et al. reported that AHR is greater in those sensitized to ragweed, ${ }^{17}$ and Chinn et al. reported an association with timothy grass sensitization. ${ }^{18}$ The subjects of these studies were children or young adults. Our study also showed that group I was affected by pollen but group II (elderly) was not. Therefore, age should be considered when examining the effects of allergens on AHR.

Allergen sensitization rates are lower in the elderly than in younger populations. ${ }^{19}$ Our study showed that the elderly have a high prevalence of asthma and a low prevalence of atopy. Asthma in older patients is usually characterized as nonatopic. ${ }^{20,21}$ The mechanisms for decreased antigen sensitization with aging are not well understood. However, the association between aging and changes in B- and T-cell function, which affect antigen presentation, and B-cell memory and cytokine profiles may explain the decrease in allergen sensitization. ${ }^{22}$ Furthermore, it is possible that older patients have become more tolerant or desensitized to specific antigens. An increased prevalence of allergen sensitization during the early decades of life followed by a decrease later in life has been described previously. ${ }^{23,24}$ However, some studies have suggested that sensitization may play a role in later-onset asthma. Litonjua et al. showed that men who develop AHR after 49 years of age are more likely to be sensitized to cats. ${ }^{25}$ One study reported that patients who develop asthma after 65 years of age are more atopic than patients who develop asthma at < 65 years. ${ }^{26}$ Bakos et al. determined that aeroallergen sensitization is associated with smoking in the elderly, which results in chronic damage to the respiratory epithelia. ${ }^{27}$ This finding suggests the need to consider other mechanisms of sensitization and the development of asthma in the elderly, and not just age, when analyzing the effects of sensitization and AHR.

Several limitations of our study should be discussed. The study population was from a single institution, and only patients with airway symptoms were included. As this study included patients who underwent skin prick tests, asthma was the most frequent diagnosis, and the frequency of COPD was low. Therefore, our results do not represent the allergen sensitization pattern of all patients with a respiratory disease. This study included patients without asthma, and there were also non-asthmatic patients with positive AHR. However, the aim of our study was to investigate the effect of aeroallergen sensitization on AHR and, thus, we did not exclude them. Another limitation is that we did not consider the differences in allergen exposure and the timing of the tests. AHR could be affected by the degree of exposure to the allergens. In cases of pollen sensitization, the degree of AHR may vary according to season. In this study, positive AHR and pollen sensitization were related, but the severity of AHR did not correlate with the wheal size produced by the pollen. This might be because we did not consider the seasonal effect of pollen. Nevertheless, we believe that this study was meaningful in that it confirmed the effect of pollen on AHR, unlike most previous studies. Although we analyzed only 16 selected allergens, we should consider that HDM and tree pollen sensitization are frequent in Busan, and that they have a significant impact on AHR, considering the effect of $D$. farina and oak.

\section{Conclusion}

Sensitization to HDM and tree pollen was found to be common in Busan. These aeroallergens significantly affected AHR, particularly in the younger group, and were found to be independent factors for AHR.

\section{Author Contributions}

- Eun-Jung Jo: conception and design of the study, acquisition of data, interpretation of the data, and preparation of the manuscript

- Jung Seop Eom, Jeongha Mok, Mi-Hyun Kim, Kwangha Lee, Ki Uk Kim, Min Ki Lee: conception and design of the study, acquisition of data, and interpretation of the data

- Hye-Kyung Park: conception and design of the study, interpretation of the data, and preparation and critical revision of the manuscript

\section{Financial support}

This research did not receive any specific grant from funding agencies in the public, commercial, or not-for-profit sectors.

\section{Conflicts of interest}

There are no potential conflicts of interest related to this article or the research described.

\section{References}

1. Sears MR, Burrows B, Flannery EM, Herbison GP, Holdaway MD. Atopy in childhood. I. Gender and allergen related risks for development of hay fever and asthma. Clin Exp Allergy. 1993;23:941-8.

2. Jaakkola MS, Ieromnimon A, Jaakkola JJ. Are atopy and specific IgE to mites and molds important for adult asthma? J Allergy Clin Immunol. 2006;117:642-8.

3. Chinn S, Heinrich J, Anto JM, Janson C, Norback D, Olivieri M, et al. Bronchial responsiveness in atopic adults increases with exposure to cat allergen. Am J Respir Crit Care Med. 2007;176:20-6.

4. Sears MR, Herbison GP, Holdaway MD, Hewitt CJ, Flannery EM, Silva PA. The relative risks of sensitivity to grass pollen, house dust mite and cat dander in the development of childhood asthma. Clin Exp Allergy. 1989;19:419-24.

5. Jo EJ, Kim MY, Lee SE, Lee SY, Kim MH, Song WJ, et al. Eosinophilic airway inflammation and airway hyperresponsiveness according to aeroallergen sensitization pattern in patients with lower airway symptoms. Allergy Asthma Immunol Res. 2014;6:39-46.

6. Sohn SW, Lee HS, Park HW, Chang YS, Kim YK, Cho SH, et al. Evaluation of cytokine mRNA in induced sputum from patients with allergic rhinitis: relationship to airway hyperresponsiveness. Allergy. 2008;63:268-73.

7. Kang MG, Kim MY, Song WJ, Kim S, Jo EJ, Lee SE, et al. Patterns of inhalant allergen sensitization and geographical variation in Korean adults: a multicenter retrospective study. Allergy Asthma Immunol Res. 2017;9:499-508.

8. Kim KH, Kim KT, Lee SK, Park HS, Lee YM, Nahm DH, et al. Sensitization rates for inhalant allergens in patients with respiratory allergy in Busan. Korean J Asthma Allergy Clin Immunol. 2005;25:59-63.

9. Lee JW, Choi GS, Kim JE, Jin HJ, Kim JH, Ye YM, et al. Changes in sensitization rates to pollen allergens in allergic patients in the southern part of Gyeonggi province over the last 10 years. Korean J Asthma Allergy Clin Immunol. 2011;31:33-40. 
10. Oncham S, Udomsubpayakul U, Laisuan W. Skin prick test reactivity to aeroallergens in adult allergy clinic in Thailand: a 12-year retrospective study. Asia Pac Allergy. 2018;8:e17.

11. Kim BS, Jin HS, Kim HB, Lee SY, Kim JH, Kwon JW, et al. Airway hyperresponsiveness is associated with total serum immunoglobulin $\mathrm{E}$ and sensitization to aeroallergens in Korean adolescents. Pediatr Pulmonol. 2010;45:1220-7.

12. Omenaas E, Bakke P, Eide G, Elsayed S, Gulsvik A. Serum house dust mite antibodies: predictor of increased bronchial responsiveness in adults of a community. Eur Respir J. 1996;9:919-25.

13. Kerkhof M, Postma D, Schouten J, De Monchy J. Allergic sensitization to indoor and outdoor allergens and relevance to bronchial hyperresponsiveness in younger and older subjects. Allergy. 2003;58: 1261-7.

14. Boulet LP, Gauvreau G, Boulay ME, O’byrne P, Cockcroft D. Allergen -induced early and late asthmatic responses to inhaled seasonal and perennial allergens. Clin Exp Allergy. 2015;45:1647-53.

15. Park KJ, Kim H, Kim KR, Oh JW, Lee SY, Choi YJ. Characteristics of regional distribution of pollen concentration in Korean Peninsula. Korean J Agric For Meteorol. 2008;10:167-76.

16. Tham EH, Lee AJ, Bever H. Aeroallergen sensitization and allergic disease phenotypes in Asia. Asian Pac J Allergy Immunol. 2016;34:181-9.

17. TePas EC, Litonjua AA, Celedón JC, Sredl D, Gold DR. Sensitization to aeroallergens and airway hyperresponsiveness at 7 years of age. Chest. 2006;129:1500-8

18. Chinn S, Burney P, Sunyer J, Jarvis D, Luczynska C. Sensitization to individual allergens and bronchial responsiveness in the ECRHS. European Community Respiratory Health Survey. Eur Respir J. 1999;14:876-84.
19. Wüthrich B, Schmid-Grendelmeier P, Schindler C, Imboden M, Bircher A, Zemp E, et al. Prevalence of atopy and respiratory allergic diseases in the elderly SAPALDIA population. Int Arch Allergy Immunol. 2013;162:143-8.

20. Braman SS, Kaemmerlen JT, Davis SM. Asthma in the elderly: a comparison between patients with recently acquired and long-standing disease. Am Rev Respir Dis. 1991;143:336-40.

21. Busse PJ, Lurslurchachai L, Sampson HA, Halm EA, Wisnivesky J. Perennial allergen-specific immunoglobulin E levels among inner-city elderly asthmatics. J Asthma. 2010;47:781-5.

22. Agarwal S, Busse PJ. Innate and adaptive immunosenescence. Ann Allergy Asthma Immunol. 2010;104:183-90.

23. Lombardi C, Passalacqua G, Gargioni S, Senna G, Ciprandi G, Scordamaglia A, et al. The natural history of respiratory allergy: a follow-up study of 99 patients up to 10 years. Respir Med. 2001;95:9-12.

24. Eriksson N, Holmen A. Skin prick tests with standardized extracts of inhalant allergens in 7099 adult patients with asthma or rhinitis: cross -sensitizations and relationships to age, sex, month of birth and year of testing. J Investig Allergol Clin Immunol. 1996;6:36-46.

25. Litonjua AA, Sparrow D, Weiss ST, O’connor GT, Long AA, Ohman Jr JL. Sensitization to cat allergen is associated with asthma in older men and predicts new-onset airway hyperresponsiveness: the Normative Aging Study. Am J Respir Crit Care Med. 1997;156:23-7.

26. Ariano R, Panzani R, Augeri G. Late onset asthma clinical and immunological data: importance of allergy. J Investig Allergol Clin Immunol. 1998;8:35-41.

27. Bakos N, Schöll I, Szalai K, Kundi M, Untersmayr E, Jensen-Jarolim E. Risk assessment in elderly for sensitization to food and respiratory allergens. Immunol Lett. 2006;107:15-21. 